\title{
UPGRADE OF THE SRS KLYSTRON POWER SUPPLY
}

\author{
A.J.Moss, R.J.Smith \& S.A.Griffiths \\ Daresbury Laboratory, Daresbury, Warrington, WA44AD, UK
}

\begin{abstract}
The Radio Frequency system for the $2 \mathrm{GeV}$ Synchrotron Radiation Source (SRS), at Daresbury Laboratory consists of a $250 \mathrm{~kW}$ Klystron feeding four normal conducting cavities via a waveguide feeder system. The Klystron power converter is a $50 \mathrm{kV} 15 \mathrm{Amp}$ conventional roller regulator 6-pulse rectifier set with capacitor smoothing, giving an energy storage of $27 \mathrm{~kJ}$. There is a 'crowbar' system using 4 ignitrons in series, this dumps the stored energy in $6 \mu \mathrm{S}$ for the protection of the Klystron under spark conditions. Control of the Klystron output is by adjustment of the modulating anode voltage with a $50 \mathrm{kV}$ high voltage power supply incorporated within the main power converter. The power converter was designed and built 25 years ago and is now giving poor reliability, and is difficult and time consuming to maintain. Almost all the problems can be traced to the 'crowbar' and modulation anode system causing false firing of the protection circuits.
\end{abstract}

\section{INTRODUCTION}

The decision to replace the power converter necessitated a process of discussions with other light sources, to find out what types of power converter were in use and gain information on system operational issues. To this end Daresbury personnel visited the ANKA, ESRF, SLS light sources and Marconi (formally EEV) and had discussions with numerous companies in the USA. The investigations brought up many different designs, some conventional others more novel; this paper sets out to discuss our findings.

\section{COMPARISON OF SYSTEMS}

\subsection{Conventional crowbar systems}

The Klystron test stand at Marconi is a conventional crowbar system for conditioning Klystrons, prior to customer delivery. The system employs a primary line commutated thyristor system and step-up transformer, to provide the high voltage DC. This is smoothed by a conventional LCR circuit. Klystron protection is provided by a conventional crowbar system based around a thyratron switch. RF output power is controlled by modulation of RF drive. Similar crowbar systems, built by Siemens for the ESRF, have now been in full time operation for 8 years with good reliability, and as such were also considered as part of this assessment. Klystron protection within these supplies is provided by fast $\mathrm{DC}$ current transformers applied to the earth return circuit, to sense current surges, which could indicate an internal Klystron spark. This initiates a thyratron fired series ignitron based crowbar. Control of RF power output is via RF drive modulation, with overall control of the klystron modulation anode via a DC power supply referenced to the klyston cathode.

Another system developed by Maxwell Technologies (now Titan Pulsed Science) for the Accelerator Production of Tritium (APT) project produced $95 \mathrm{kV}$ at 21A using silicon controlled rectifier (SCR) controllers and a step-up transformer with crowbar protection. Four of these units have been in operation since 1999 and have successfully protected the Klystrons against numerous arcs.

\subsection{Low stored energy technique}

The Jaeger PSU at the ANKA storage ring is a distributed system, consisting of step-down transformer, SCR regulator, step-up transformer and power factor correction. The major HV components are located in an air-conditioned room (see Fig 1). An inductor in the output of the PSU (see Fig2.) limits the energy available to a fast rising pulse (a spark) so that the system can be switched off before any damage to the Klystron can take place.

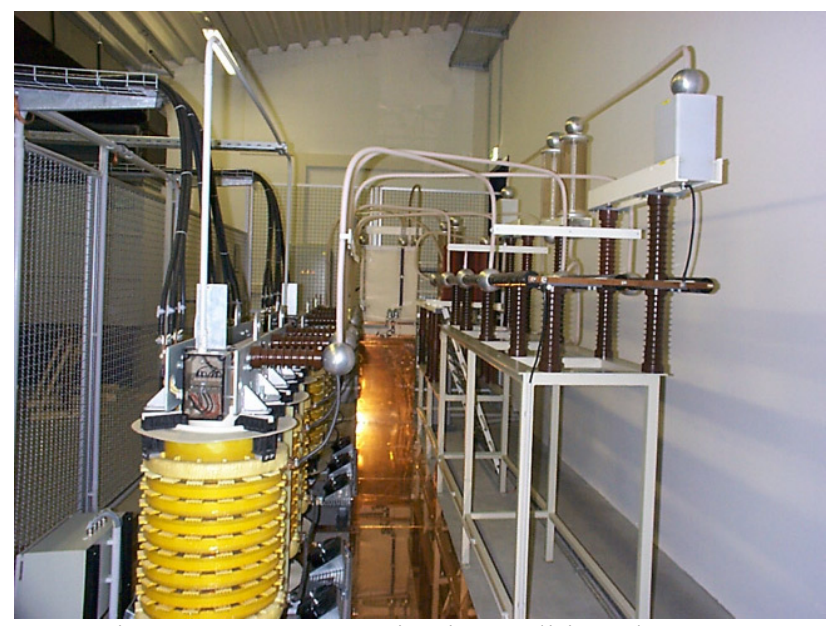

Fig.1. ANKA HVPC in air-conditioned room.

The system uses a fixed potential divider located close to the klystron to supply the modulation anode and the RF power is then controlled using RF drive modulation. The klystron is located some 40 metres from the filter components in the HV room, yet the stored energy in the system remains below 20J and the system switches off in 
$<20 \mathrm{mS}$ in the event of a fault. ANKA have operated two of these systems for over a year without operation faults.

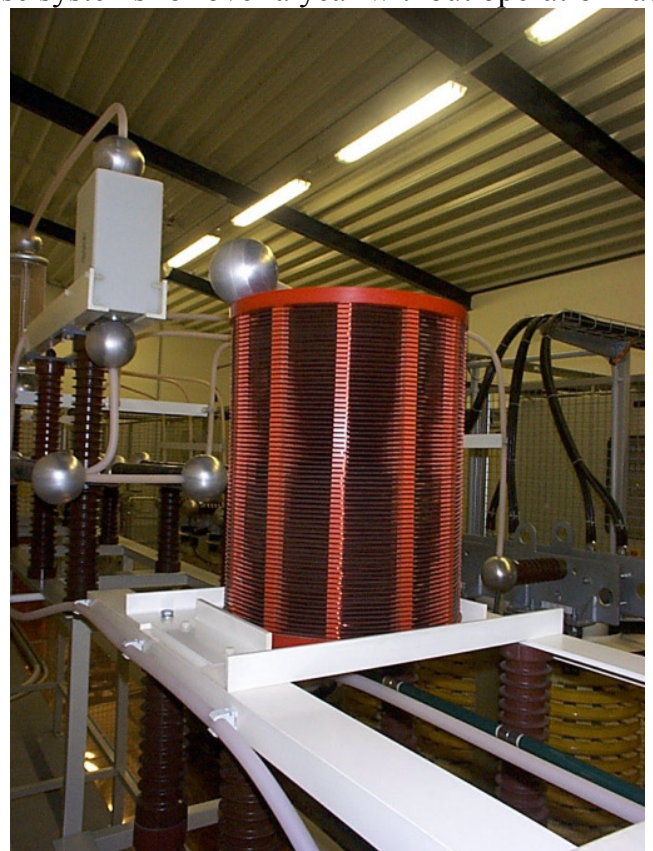

Fig 2. High voltage inductor on output of Jaeger HVPC

\subsection{High frequency modulator technique}

The Swiss Light Source uses a commercial Thomcast pulse step modulator to provide $46 \mathrm{kV}$ at $7.5 \mathrm{~A}$. The SLS has 5 such systems to power individual klystron sets. The system uses a 3-phase $400 \mathrm{~V}$ input and is relatively compact at $6 \mathrm{~m}$ by $2 \mathrm{~m}$ see Figure 3. A modular build system is used, with 68 modules (Figure 4) each supplying approximately $800 \mathrm{~V}$ depending on required output voltage. The modules are connected to the isolated secondary of a complex transformer delivering a 3 phase supply to each module.

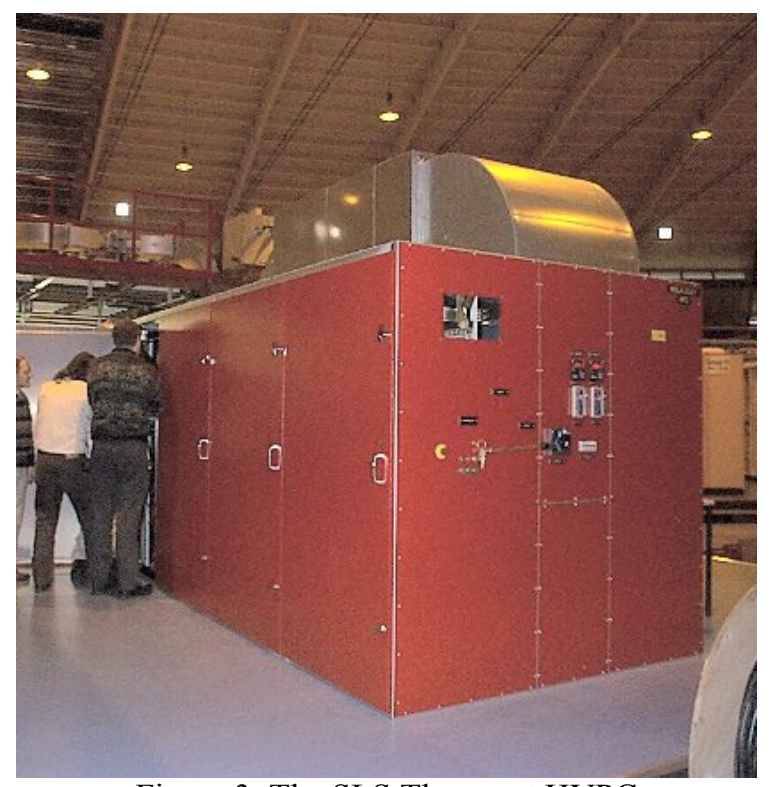

Figure 3. The SLS Thomcast HVPC
The system is situated close to the klystron and uses power supplies located on a internal high voltage deck to supply the klystron modulation anode and heater.

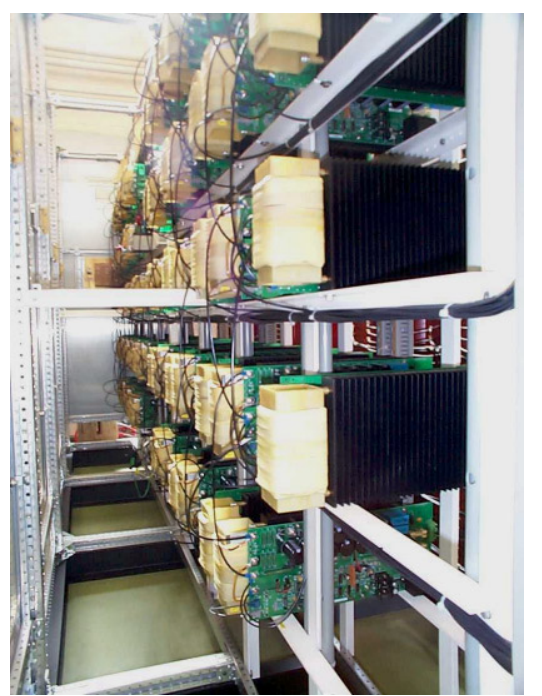

Fig 4 Modules inside the Thomcast HVPC

The Thomcast system also monitors and interlocks all parameters for a complete RF cavity system using its EPICS based control system. This allows remote and local diagnostics of all aspects of each RF system to be investigated, controlled and adjusted. The SLS report no operation problems in one year although development of the PSU continues.

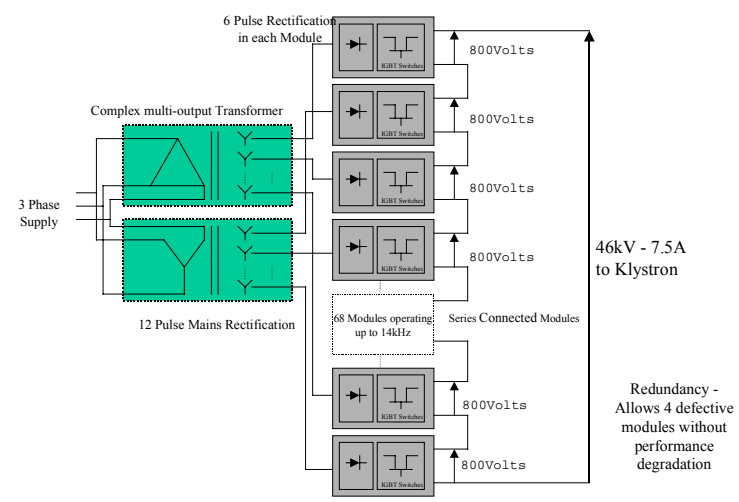

Fig 5. Thomcast Pulse Step modulator 46kV 7.5A

Titan Pulsed Sciences have built a similar system for the APT project using Insulated Gate Bipolar Transistors (IGBT) controlled Solid State Modulators. 96 modules connected in series produced $95 \mathrm{kV}$ at $21 \mathrm{~A}$. In both systems there is module redundancy allowing up to four modules to fail before the performance is comprimised.

\subsection{Solid-state modulator}

Diversified Technologies Inc. [1] have built numerous systems for modulating high voltage using their patented solid state switch modules, see Figure 6. A system built 
for Communication and Power Industries (CPI) in Palo Alto, California, uses a bank of switches to provide a $140 \mathrm{kV} 500 \mathrm{~A}$ modulator for conditioning Klystrons. A second switch, rated at $160 \mathrm{kV}, 3.2 \mathrm{MW}$ continuous, is the key element of a buck regulator power supply driving the modulator.

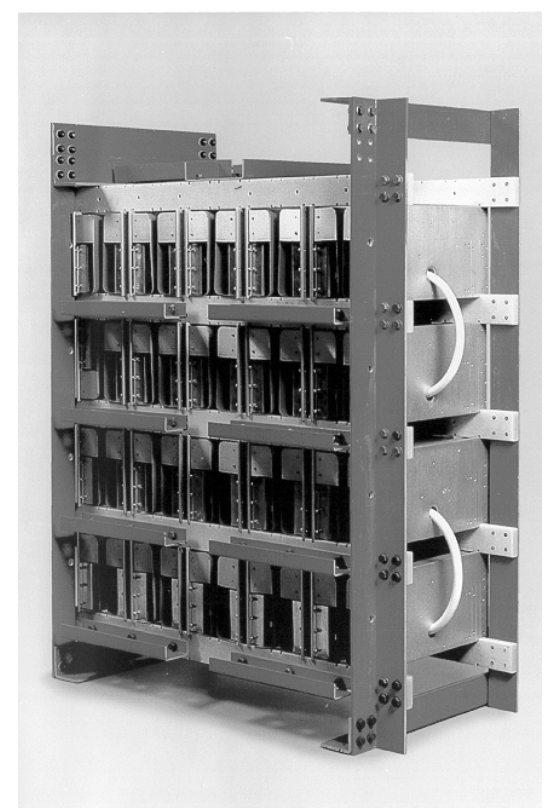

Fig 6 DTI Solid State Switch 140kV 500A[2]

Generation of the unregulated HV is done using a stepup transformer and rectifier with smoothing. The switching buck regulator housing the solid-state switch modules, is used to stabilise and control the DC output see Figure 7. The second, series switch, acts as a modulator, and controls the power supplied to the klystron. These systems have generally been used for pulse modulation applications, although using some derating of the series switch modules the system becomes, in effect, a fast disconnector for klystrons. The system allows switching times in the hundred nanoseconds region. In the event of a klystron spark, less energy is deposited in the tube than in the case of a conventional crowbar system.

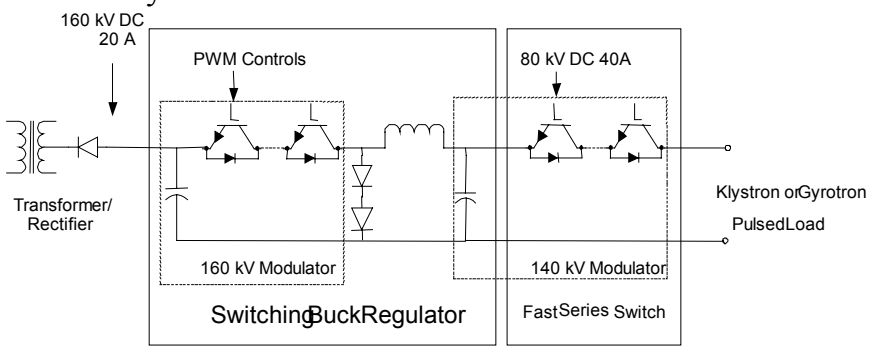

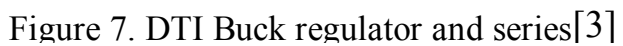

The control electronics monitors the current passing though the switch in comparison with a user set trip limit, and disconnects the klystron in $<700 \mathrm{nS}$. An interesting demonstration was made at the Advanced Photon Source. The beam remained in the machine while the RF was blanked for 30us. The opening switch can open or close in less than 1us. If a klystron fault can be cleared within this 30 us, the beam will continue circulating despite a klystron fault.

\section{CONCLUSIONS}

Since the SRS Klystron power converter was designed, almost 25 years ago, protection of klystrons has developed significantly. Klystrons themselves have become more robust and require less stringent protection.

The trend seems to be away from ignitron based crowbar systems, towards low stored energy systems.

The stress put on the electricity system of a light source when a crowbar occurs needs to be avoided as much as possible, experience at Daresbury has shown the site lighting system dip during a crowbar sequence. The energy involved in a crowbar action often means that detecting what caused the problem, klystron spark or problem within the power converter itself, can be impossible to trace since so many interlocks fail as a result of the disturbance to the electrical system.

With more development of IGBT semiconductors in recent years, these devices are now able to be incorporated in high voltage applications where there simply was no option other than a conventional Thyratron/Ignitron solution 10 years ago. The efficiency and running costs of modulators built using this technology is now very high. In addition due to the switching speeds of this technology, low stored energy within the power supply negates the need for a crowbar system since simply switching off the oscillators driving the IGBT's prevents any possible damage to the klystron.

The decision over which power converter to purchase for the SRS has yet to be taken. What is clear is that all the systems installed in the light sources we saw would be suitable for our machine. Experience at the ESRF has shown that a modern crowbar system is very reliable; likewise at the SLS and ANKA no problems have occurred with their newer designs. The DTI solid state switch is an interesting and novel approach to klystron protection that appears to offer the potential to clear klystron faults without stopping the machine.

\section{REFERENCES}

[1] M Gaudreau, et al, "Solid State Modulator For Klystron/Gyrotron Conditioning, Testing and Operation"http://www.divtecs.com/

[2] \& [3] Courtesy of Diversified Technology Inc 